\title{
O EXERCÍCIO DEMOCRÁTICO NO SÉCULO XXI SOB A INFLUÊNCIA DOS ALGORITMOS
}

\author{
Democracy in the 21st Century under the Influence of Algorithms
}

José Everton da Silva

Marcos Vinícius de Almeida e Souza

Matheus de Andrade Branco

Resumo: O presente artigo busca aclarar a influência dos algoritmos no exercício democrático relativo às eleições e a participação popular. Tem como objetivo geral a análise do impacto dos algoritmos no exercício e processos democráticos frente à disseminação de informações falsas e o discurso de ódio. A Democracia é replicada na maior parte dos Estados em âmbito global, e traz como uma de suas premissas a participação dos eleitores no processo de escolha de seus representantes. $\mathrm{Na}$ modalidade Representativa, os cidadãos podem escolher seus representantes, para que legislem e defendam interesses da coletividade. Entretanto, com o advento das novas formas de comunicação, há uma falta de confiança na Democracia, agravada pelo sentimento de falta de Representação. A tecnologia, por intermédio dos processos comunicacionais virtuais, das redes sociais online, e da velocidade e fluxo das informações, auxilia na inclusão social dos cidadãos, que dispõem de uma nova ferramenta de participação pública, além da oportunidade de expor suas opiniões de forma mais rápida, com maior alcance e, por vezes, anônima, mas também pode acentuar ainda mais a crise representativa, visto que a divulgação e disseminação de informações falsas coloca em xeque o exercício democrático.

Palavras-chave: Democracia. Representação. Algoritmos. Notícias falsas.

\begin{abstract}
This article seeks to clarify the influence of algorithms in democracy regarding elections and popular participation. Democracy is globally widespread and characterized by elections where people choose their representatives to create laws and defend the interests of the community. However, globalization and new forms of communication have led to diffidence toward representative democracy. Technology helps citizens' social inclusion through virtual communication processes, social media, and the speed and flow of information. Citizens have gained new tools for public participation and are able to express opinions faster, with greater reach and, sometimes, anonymity. However, this scenario can also increase the crisis in representativeness due to the dissemination of fake news that jeopardizes reputations and puts democracy at risk. This article aims to analyze the impact of algorithms in democracy in the face of the dissemination of fake news.
\end{abstract}

Keywords: Democracy. Representation. Algorithms. Fake news.

Artigo recebido em 25 mar. 2021 e aprovado em 30 jun. 2021

Editor responsável: Luiz Magno Pinto Bastos Junior

DOI: https://doi.org/10.53323/resenhaeleitoral.v25i1.132 


\section{Introdução}

Para todos os lados que se olha, o que se vê é um mundo cada vez mais tecnológico, com a tecnologia num processo avassalador de evolução, tornando rapidamente obsoleto aquilo que há pouco tempo era novidade. Nessa conjuntura, a cada dia que passa as pessoas têm acesso a uma gama de informações dos modos tradicionais, tais como a televisão, o rádio e o jornal, mas, principalmente, aparelhos conectados à rede mundial de computadores. Por meio da internet pode-se receber, em tempo recorde, notícias detalhadas de um acontecimento que ocorreu do outro lado do planeta, tornando verdadeira a expressão mundo global na palma da mão.

Contudo, por serem descentralizadas, as redes virtuais trazem problemáticas que estão além da capacidade de serem solucionadas institucionalmente. Demanda um estudo interdisciplinar, que leve em conta os diversos campos de estudo e avaliação sobre o tema, que passam pela política, o direito, a tecnologia da informação, dentre outras. Nesta conjuntura, as redes sociais online têm um papel de extrema relevância no modo como encaram-se os processos políticos nos dias atuais, visto que englobam interações e opiniões, além de serem ferramentas importantes na construção de narrativas e nos processos de escolhas e formação de lideranças, sendo, portanto, peças-chave de acesso e manutenção do poder, dentro da via democrática.

Deste modo, é visível a facilidade com a qual as informações transitam por meios digitais, e o poder de difusão de uma notícia disponibilizada online. Entretanto, assim como uma notícia verídica com certa relevância se alastra facilmente, assim também pode ocorrer com informações falsas ou descontextualizadas.

Esta pesquisa tem como objetivo investigatório geral analisar o impacto dos algoritmos no exercício e processos democráticos, frente à disseminação de informações falsas e o discurso de ódio. Os objetivos específicos consistem em: i) caracterizar a Democracia, enquanto modelo político, definindo suas peculiaridades e preceitos; ii) explicitar a relação entre a Democracia e as redes em relação à difusão da participação democrática; iii) demonstrar de que modo os algoritmos podem ser utilizados como ferramenta de ameaça à ordem democrática.

A temática guarda extrema relevância no contexto político atual, visto que há grande preocupação da população, em âmbito global, com os 
efeitos políticos da desinformação oriunda de notícias espalhadas via redes sociais online e demais veículos de interação tecnológica. O problema essencial por trás da presente pesquisa é o seguinte: a evolução dos algoritmos frente à disseminação de informações falsas e o discurso de ódio é uma ameaça ao livre exercício democrático?

A partir deste problema, levantou-se a hipótese de que o desenvolvimento e aperfeiçoamento da tecnologia, especialmente no âmbito comunicacional, facilitou o acesso à informação num primeiro momento. Entretanto, devido à facilidade de difusão de notícias e o potencial alcance das informações por meio das redes sociais, uma notícia falsa ou descontextualizada, bem como a destruição da reputação de uma pessoa pública pode acabar influenciando no livre exercício da Democracia. A velocidade e o excesso de informações as quais as pessoas estão submetidas cotidianamente podem ser prejudiciais ao livre exercício democrático, devido às dificuldades de separação das informações falsas das verdadeiras.

Com vistas ao alcance dos objetivos, bem como responder ao problema, mediante confirmação ou não da hipótese apresentada, será analisada a Democracia, em um primeiro momento, visando demonstrar as suas características e, posteriormente, expor uma síntese da sua forma representativa. Este subitem é de importante relevância no contexto da pesquisa, visto que a Democracia, em que pese seja um regime complexo, criticado, e que para muitos atravessa um período de crise, ainda é o modelo idealizado e adotado por boa parte dos Estados ao redor do globo, especialmente em sua forma Representativa; ademais, será analisado de que modo os algoritmos influenciam na escolha dos representantes pelos representados; e, por fim, será exposto o risco de subversão do regime democrático frente a esta nova realidade virtual, de engajamento para propagação de notícias falsas e discurso de ódio, assim como as formas de combate a este problema.

O artigo é fruto das pesquisas realizadas no Curso de Doutorado do Programa de Pós-Graduação Stricto Sensu em Ciência Jurídica, da Universidade do Vale do Itajaí, e tem sua temática interligada com a linha de pesquisa Estado, Transnacionalidade e Sustentabilidade.

Quanto à metodologia utilizada, na fase de Investigação foi empregado o método indutivo; na fase de Tratamento dos Dados o cartesiano, e, o texto final foi assentado na base lógica indutiva. Nas diversas fases da pesquisa, foram acionadas as Técnicas do Referente, da Categoria, do Conceito Operacional e da Pesquisa Bibliográfica (PASOLD, 2018). 


\section{DEMOCRACIA}

Tratar do conceito de Democracia é tarefa das mais árduas no atual contexto mundial, especialmente quando se tem a pretensão de fazê-lo de modo sério. Essa complexidade é de tal magnitude que, em que pese haja uma gama exaustiva de escritas a seu respeito, não há como delimitar exatamente uma única teoria relacionada. Ademais, com o advento da globalização, difundiu-se num ideal de parte significativa do mundo que defende suas ideais e objetivos. Ou seja, existe material e pesquisa o suficiente para incontáveis investigações.

Com o intuito de delimitar o conceito de Democracia, será abordado o tema conforme a análise de autores que seguem linhas semelhantes, bem como uma perspectiva mais contemporânea, com a devida vênia aos pensadores clássicos, visto que sem estes não haveria como moldar os estudos acerca do fenômeno democrático. Neste sentido, ainda que haja uma roupagem semelhante às instituições políticas nos modelos antigos de Democracia e República, na íntegra, trata-se de um sistema político completamente inovador (DAHL, 2001).

Atualmente, existem diversas definições do termo Democracia, dentre estas a Democracia Deliberativa, Discursiva, Corporativista, Elitista, Dualista, Mínima, Republicana, Digital, dentre outras. Sendo assim, pode-se compreender que este modelo é muito apreciado, ou que sua definição é vaga a ponto de que qualquer definição a ela atribuída seja cabível (FARIA, 2020, p. 35).

Registradas estas considerações iniciais, é de grande importância conceituar a Democracia, conforme o referente do presente trabalho. Conforme já mencionado, serão levados em conta os estudos mais contemporâneos acerca do fenômeno, entretanto é imperativo rememorar o conceito elaborado por Kelsen (2000, p. 35), dado o fato de que o autor aponta a essência deste fenômeno como "modelo político segundo o qual as deliberações que dizem respeito à coletividade são tomadas não diretamente por seus integrantes, mas por pessoas eleitas para esta finalidade".

Complementar à definição kelseniana, Melo (1978, p. 32) elucida que a Democracia pode ser entendida como um regime político que estabelece igualdade de todos perante a lei, resguarda os direitos sociais, bem como os individuais, e garante o poder da maioria, manifestado pelo voto, no processo eleitoral. 
Ferrajoli (2011, p. 36) traz uma perspectiva constitucional ao conceito, em complemento ao sentido puramente político, tratando de Democracia constitucional, dado o fato de que engloba, sincronicamente, direitos e garantias fundamentais que devem nortear um regime genuinamente democrático. Neste sentido, conceitua-a como:

[...] modelo normativo articulado en varias dimensiones, correspondientes a otras tantas clases de derechos fundamentales: Ia democracia política, asegurada por las garantías de los derechos políticos; la democracia civil, asegurada por las garantías de los derechos civiles; la democracia liberal (o liberal-democracia) asegurada por las garantías de los derechos de libertad; la democracia social (o social-democracia), asegurada por las garantías de los derechos sociales (FERRAJOLI, 2011, p. 36, tradução nossa) ${ }^{1}$.

Portanto, no contexto estatal, pode ser representada na forma de um Estado Democrático e de Direito, que nas palavras de Cruz (2002, p. 153), é "aquele que intervém nos domínios econômico, social e cultural, obedecidos os parâmetros mínimos de cidadania política, justiça, representatividade, legalidade e legitimidade". Outrossim, é oportuno definir e diferenciar os conceitos da Democracia Formal e da Democracia Substancial. Em síntese, pode-se dizer que a Democracia formal é verificada como um meio utilizado para a tomada de decisões, abarcando as eleições livres e periódicas, e o sufrágio universal, entre outras garantias, ao passo que a Democracia Substancial têm seu conceito ligado a valores de igualdade, paz e outros similares, e aos direitos fundamentais, no sentido de que contraponham a arbitrariedade da maioria, impondo limites ao poder dela. Tem um modelo tetradimensional, segundo a qual a Democracia se articula na dimensão dos direitos políticos, dos direitos civis, dos direitos de liberdade e dos direitos sociais. Em suma, pode-se concluir que, quando trata-se da Democracia como governo do povo para o povo, a Democracia Formal é um governo do povo, à medida que a Democracia Substancial é um governo para o povo (FARIA, 2020, p. 122-123).

1 “[...] modelo normativo articulado em várias dimensões, correspondentes a outras tantas classes de direitos fundamentais: a democracia política, assegurada pelas garantias dos direitos políticos; a democracia civil, assegurada pelas garantias dos direitos civis; a democracia liberal (ou liberal-democracia) assegurada pelas garantias dos direitos de liberdade; a democracia social (ou social-democracia), assegurada pelas garantias dos direitos sociais.". 
Em tempo, cabe mencionar também que para uma parte dos estudiosos, o Estado e a Democracia enfrentam uma crise em suas estruturas, influenciada por diversos fatores, dentre os quais a globalização e a desconfiança em relação à representatividade. Em consonância com tal pensamento, Sassen (2010, p. 17-18) expõe que a hierarquia centrada no Estado Moderno têm perdido estabilidade frente aos processos e formações globais. Ainda, entende que as antigas hierarquias constituídas como parte do desenvolvimento do Estado-Nação permanecem operando, entretanto isto ocorre num campo menos exclusivo que anteriormente, inclusive no que tange ao poder hegemônico, visto que a soberania não é mais plena, na prática.

Para além do problema com as estruturas do Estado, influências de atores internacionais na engrenagem político-estatal reverberam na própria Democracia. Esta realidade resulta em privilégios às empresas e às organizações transnacionais, com foco econômico em demasia em detrimento às demandas sociais. A consequência disto é a insatisfação popular com a classe política, cuja representação é questionada, visto que são eleitos para expressar a vontade do povo, entretanto acabam por não ter a força para tanto. Nesta conjuntura, sustentam Hessel e Morin (2012, p. 35, tradução nossa) que a "a crise das Democracias é agravada pela crise econômica, e ambas combinadas promovem a ascensão dos extremos [...]"2. Portanto, denota-se que há uma certa desconfiança e pessimismo em relação à Democracia, que pode ocasionar consequências perigosas para o exercício democrático pleno.

Diante deste cenário, é importante demonstrar de que modo aflui o exercício democrático atual, para posteriormente questionar a influência, positiva ou negativa, dos algoritmos nesse processo.

\subsection{REPRESENTAÇÃO EDEMOCRACIAREPRESENTATIVA}

Antes de adentrar à análise da Democracia em sua forma representativa, é conveniente entender do que se trata o fenômeno da representação, de modo a defini-la sob tal perspectiva. Na acepção de Melo (1978, p. 84-85), quando trata da Representação “[...] na linguagem geral do Direito, é o conjunto de poderes atribuídos a uma pessoa para a prática de atos em

${ }^{2}$ [...] "la crisis de las democracias se ve agravada por la crisis económica, y ambas combinadas propician el ascenso de los extremos [...]." 
nome de outrem. [...] num contexto de Teoria Legislativa, a prerrogativa do eleito para legislar em nome dos eleitores".

Para Cotta (apud BOBBIO; MAT'TEUCCI; PASQUINO, 2007, p. 1101-1107) , o significado da Representação manifesta-se de melhor maneira se observado como um regime político representativo contrapõe regimes absolutistas e aristocráticos, retirados do controle do povo, bem como contrapõe também a forma de Democracia direta, regime no qual não há, em tese, distinção entre governantes e governados. Assim sendo, entende que o sentido desta representação está na perspectiva de controle político de quem não pode, pessoalmente, exercer o poder.

Ademais, Abreu (2008, p. 170-171) sustenta que o conceito de Representação Política é movido por fatores, a saber: o surgimento e ampliação das organizações políticas em diversos Estados; o direito ao voto é mais ampliado; a responsabilidade dos governantes perante órgãos de representação, diante de seus atos; a submissão das assembleias hereditárias às eleitas.

De modo similar ao exposto pelos autores mencionados, Faria sustenta que há uma razão para existência da Representação Política, a qual se concretiza no modo pelo qual determinadas pessoas se elevam ao poder e, a partir de então, são capazes de agir em nome das demais, cabendo aos representados, dentro da legalidade e regularidade, a decisão de quem irá representá-los (FARIA, 2020, p. 123).

Vencidas as considerações acerca da Representação Política, cabe sintetizar a temática da Democracia Representativa. Denota-se que esta tem uma história relativamente recente, na qual ocorreu uma grande contribuição dos chamados "pais fundadores" dos Estados Unidos. Neste contexto, a partir do século XVIII, a ideia de que pessoas recebem um mandato, mediante eleições livres, com a incumbência de atuar representando interesses de uma sociedade difundiu-se no Ocidente. Desde então, em essência, as instituições democráticas conservam a mesma essência, ainda que o mundo tenha passado por uma transformação radical. Sociedades que até então eram simples, paulatinamente transformaram-se em democracias complexas e de massas, como observado atualmente (ABREU, 2008, p. 189).

É importante destacar a definição de Bobbio (2000, p. 56) de que se trata de um "modelo político segundo o qual as deliberações que dizem respeito à coletividade são tomadas não diretamente por seus integrantes, 
mas por pessoas eleitas para esta finalidade". Além disso, o autor também aponta dois atributos do titular do mandato numa Democracia em sua forma Representativa, quais sejam: a) em primeiro lugar, que o eleito já não é responsável perante seus eleitores, visto que detém a confiança destes, de forma a não ter seu mandato revogado; b) a tutela dos interesses deixa de ser a do eleitor em particular, sendo transferida para a sociedade. Em observância a este último atributo mencionado, Faria (2020, p. 124) expõe que na Representação Política brasileira prevaleceu a Teoria do Mandato Discricionário, a qual preceitua que o representante, quando eleito, desvincula-se do eleitor, "cujo momento de interferência deste sobre o político é o da eleição". Frente a estas constatações, resta demonstrada a importância da ideia de Representação Política na Democracia, visto que, embora seja de forma indireta e, como visto, sem vinculação pessoal do eleito para com o eleitor, é por meio desta representação que o povo exerce o poder soberano.

Quando se trata da Democracia representativa, no que tange ao pluralismo cultural, há uma via de mão dupla, pois ainda que seja idealizada para que haja uma pluralidade de interesses e vontades, o que torna necessária a disputa de pessoas que representam grupos de interesse, também acentua os déficits de legitimidade de um modelo representativo, dado que o critério majoritário é, prioritariamente, o empregado para legitimar as decisões políticas (GORCZEVISKI; FRIDERICH, 2018).

Tocqueville (2005, p. 294), em sua obra A Democracia na América: Leis e Costumes, apontou que deve haver cautela nestas decisões, que podem configurar uma tirania da maioria. Segundo a obra, o autor considera "ímpia e detestável a máxima de que, em matéria de governo, a maioria do povo tem o direito de fazer tudo". Ademais, pontua que "existe uma lei geral que foi feita ou, pelo menos, adotada não apenas pela maioria deste ou daquele povo, mas pela maioria de todos os homens. Esta lei é a justiça”. Ou seja, segundo o autor francês, o parâmetro da Justiça é o que deve nortear os governantes e, consequentemente, as leis.

Isto posto, é essencial para o referente desta pesquisa que se examine de que modo a escolha dos representantes pelos representados pode sofrer influência de fatores tecnológicos ligados aos algoritmos. 


\section{INFLUÊNCIA DOS ALGORITMOS NA PARTICIPA- ÇÃO DEMOCRÁTICA}

O processo de desbravamento digital resultou na queda de fronteiras, o que leva à necessidade de pensar o mundo de um jeito novo. Esta era digital vem, gradativamente, transportando o palanque político que outrora se dava por meio de contato nas ruas, para as redes. Este espaço cibernético tem um alcance muito maior, além de maior velocidade de informações, que por vezes são corrompidas, com força para influenciar no pleito eleitoral, condicionando eleitores e desequilibrando as disputas (TOFFOLI, 2020).

Ainda que a influência da tecnologia não seja um fenômeno tão atual nos campos de pesquisa jurídica, o que se dá principalmente com o estudo da globalização, que desencadeou uma velocidade imensurável da informação, a questão dos algoritmos ainda é assunto de vanguarda no que tange ao Direito. Frente a esta constatação, faz-se necessário uma abordagem, em primeiro plano, do que são estes algoritmos, campo tecnológico que será objeto de abordagem do presente artigo.

Os algoritmos estão presentes de forma constante na vida das pessoas dentro do atual contexto tecnológico. São encontrados em softwares, robôs, calculadoras, veículos, aeronaves, semáforos inteligentes, mecanismos de pesquisa na internet, redes sociais, aplicativos, dentre outras inúmeras outras coisas. A utilização crescente destes algoritmos segue a acentuada digitalização da comunicação mundial, dos arquivos e expressões simbólicas, além de expressar a grande automação das atividades produtivas, tornando vital o uso de softwares (SILVEIRA, 2019, p. 17).

Algoritmo é um método de solução de problema, que depende de instruções inequívocas, regras encadeadas de modo lógico e de informações iniciais, as quais serão tratadas e processadas mediante procedimentos definidos, gerando resultados expressos em outros dados ou informações. Não obstante, pode ser compreendido também como uma sequência bem definida de etapas, utilizada para solução abstrata de um problema. Pode-se dizer que trata-se de um conjunto de instruções finitas e encadeadas numa linguagem formal, executáveis num determinável tempo. Além disso, esse conjunto de instruções deve ser preciso para que seja executado por um computador (SILVEIRA, 2019, p. 17). 
Para se ter uma noção da importância deste método, sem ele não haveria possibilidade de existir a computação, conforme expõe Goffey (apud FULLER, 2008, p. 16, tradução nossa):

Historicamente, o algoritmo ocupa uma posição central na ciência da computação em razão da forma como encapsula a lógica básica por trás da máquina de Turing. O conceito de Alan Turing de uma máquina que poderia ser utilizada para definir se algum problema particular é suscetível de ser resolvido mecanicamente foi uma interpretação altamente original do famoso projeto de David Hilbert de decidir formalmente se uma proposição matemática pode ou não ser provada. $\mathrm{O}$ algoritmo, que Turing entendeu como um processo efetivo para resolver um problema, é meramente o conjunto de instruções inseridas na máquina para resolver esse problema. Sem o algoritmo, então, não haveria computação ${ }^{3}$.

No contexto das redes sociais online, os algoritmos influenciam numa enorme gama de situações. Primeiramente, no que tange aos padrões de inclusão usados por eles, que definem, de modo claro, o que deve ou não ser incluído nas suas operações. Ademais, são projetados com vistas a antecipar a escolha do usuário em vários ciclos de antecipação. Há, também, a função da avaliação de relevância em que, por intermédio dos algoritmos, há uma classificação de quais informações são mais ou menos importantes para cada indivíduo. Nesta conjuntura, algoritmos direcionam a pesquisa aos interesses das pessoas, excluindo do campo de busca informações que reputam ser inúteis, ou contrárias ao pensamento do indivíduo.

Assimiladas estas definições, resta verificar a atuação dos algoritmos no cotidiano e, por fim, sua influência na tomada de decisão política. Com o advento do rompimento das barreiras físicas, a comunicação é levada para outro patamar, não mais aquele físico, mas a nível virtual. Entretanto, há um excesso de informação, com falta de ordenação para filtrá-la.

\footnotetext{
3 "Historically, the algorithm occupies the central position in computing science because of the way that it encapsulates the basic logic behind the Turing machine. Alan Turing's concept of a machine that could be used to determine whether any particular problem is susceptible to being solved mechanically was a highly original interpretation of the aim of David Hilbert's famous project of formally deciding whether or not any mathematical proposition can be proved true. The algorithm, which Turing understood as an effective process for solving a problem, is merely the set of instructions fed into the machine to solve that problem. Without the algorithm then, there would be no computing."
} 
Não há dúvida acerca do papel dos algoritmos na comunicação, dado que detém o poder de transformar a informação, além de, em alguns casos, classificá-la. Neste último caso, posto em contato com um conjunto de dados, selecionam os que foram predeterminados como úteis para o fim ao qual foram programados. Podem ser determinísticos, prescritivos, probabilísticos, dentre outras possibilidades, servindo como um filtro informacional. É o caso, por exemplo, das redes sociais online, organizadas por algoritmos, que determinam o que recebemos de informação de nossos amigos e seguidores, bem como o alcance de nossas publicações a estas pessoas, resultando numa bolha que interliga pessoas que têm padrões e características semelhantes (SILVEIRA, 2019, p. 20).

Para além do interesse comercial, como é o caso da utilização destas bolhas para fins de marketing das empresas responsáveis pela tecnologia e por propagandas, um fenômeno sociopolítico surgiu neste contexto, de forma mais acentuada nos últimos anos, com escândalos de interferência em eleições, manipulação de informações, dentre outros assuntos delicados que passaram a ser objeto de estudo e pesquisa.

O surgimento da internet provocou mudanças no âmbito comunicacional, entretanto, o objetivo do presente é a verificação do modo pelo qual este fenômeno interfere nas democracias. A difusão da comunicação pelo meio digital reduziu barreiras para que as pessoas pudessem se tornar emissoras de informações, permitindo que falassem mais, todavia não significou que fossem ouvidas, como afirma Luhmann (2006, p. 115), “[...] naturalmente, nem tudo o que dizemos tem sucesso comunicativo. Nem todas as mensagens que emitimos são aceitas pelos outros como premissas para o seu comportamento futuro". Ainda assim, há um certo otimismo em relação à Democracia digital, frente às possibilidades tecnológicas disponibilizadas, ainda que os mecanismos institucionalizados e a efetiva participação seja percentualmente pequena.

Por outro lado, as redes sociais têm demonstrado um poder impulsor de movimentos - no Brasil, por exemplo, as Jornadas de junho de 2013 - que demonstram insatisfação com os sistemas eleitorais, com a representação política, com os partidos e figuras políticas tradicionais, além de questionar o papel da Democracia para responder a estes problemas e expectativas sociais. Estes movimentos democráticos mostram a força e o papel das redes sociais online em relação à articulação, manifestações e 
ações coletivas nos espaços urbanos. Neste sentido, Castells (2012, p. 12) sustenta que:

Como os meios de comunicação de massa são amplamente controlados por governos e empresas de mídia, na sociedade em rede a autonomia de comunicação é basicamente construída nas redes da internet e nas plataformas de comunicação sem fio. As redes sociais digitais oferecem a possibilidade de deliberar sobre e coordenar as ações de forma amplamente desimpedida.

No entanto, na esteira destas articulações, surgiram também discursos antidemocráticos e neofascistas, que colocam em risco a própria estrutura democrática (SILVEIRA, 2019, p. 32).

O que se questiona, frente a esta realidade é a forma de resposta que será dada pela Democracia frente a estes desafios, e até mesmo se "conseguirá sobreviver à destruição de parâmetros de realidade que anulam o debate e substituem-no pelo confronto de pós-verdades"4. Aliás, quando se fala em pós-verdades ou, mais especificamente, pós-verdade, é importante salientar qual o significado do termo. Eleita pelo Dicionário Oxford, em 2016, como palavra do ano, significa "circunstâncias em que os factos objetivos têm menos influência na formação da opinião pública do que os apelos emocionais e as emoções pessoais" (FARIA, 2020, p. 166).

Num contexto em que os fatos tenham uma relevância proporcionalmente menor em relação às opiniões e emoções, a Democracia corre o risco de não passar incólume, especialmente quando inverdades surgem para colocar em xeque pessoas, reputações e o próprio regime democrático.

\section{REDES SOCIAIS, POLÍTICA E RISCO À DEMOCRA- CIA: DOS ROBÔS ÀS FAKE NEWS E O DISCURSO DE ÓDIO}

O surgimento e consolidação das redes sociais online no cotidiano dos cidadãos tornou-as uma realidade no campo da informação e na política, que são intimamente ligados. Como é sabido, a Democracia sofre inter-

\footnotetext{
${ }^{4}$ Silveira traz o conceito de pós-verdade, conforme o dicionário de Oxford, como sendo "circunstâncias nas quais os fatos objetivos são menos influentes na formação da opinião pública do que os apelos à emoção e à crença pessoal”. Disponível em: https:/ /www.lexico.com/definition/post-truth.
} 
ferência pelo modo ao qual ocorrem os processos comunicacionais. Antes da internet, os jornais, o rádio e a televisão, como meios de comunicação de massa, tiveram uma forte influência nas campanhas políticas (BRAGA apud PEREIRA, 2018, p. 203-220).

Sabe-se também que os regimes verdadeiramente democráticos devem garantir a livre manifestação do pensamento. Neste sentido, a expressão do descontentamento com a condução da coisa pública, cobranças de pautas populares, e as críticas, mesmo que duras, a um agente público, são condições indispensáveis para o exercício democrático, desde que dentro das regras do jogo constitucional (FARIA, 2020, p. 163). Assim, para além do direito de ser ouvido, é importante que seja respeitado o direito de ouvir o que outras pessoas têm a dizer, visto que o silêncio dos cidadãos é característica de ditaduras, não serve à Democracia (DAHL, 2001, p. 14).

Neste contexto, as redes sociais online, situadas na internet, gozam de interatividade, um aspecto até então não experimentado pelos outros meios de comunicação de massas tradicionais. No mundo virtual, é possível disponibilizar e compartilhar conteúdo com um custo muito reduzido, além de ter um potencial de alcance nunca antes visto. No Brasil, a título de exemplo, no ano de 2016, 168 milhões de smartphones estavam em uso, sem considerar demais terminais que têm conexão com a internet (BRAGA apud PEREIRA, 2018, p. 204).

A partir desta realidade, verifica-se uma influência de atores virtuais no exercício democrático, em ambiente mundial, o que resulta numa maior preocupação dos cidadãos em relação às escolhas políticas. Entretanto, quando se trata da temática em tela, as pessoas ainda têm dúvidas acerca de como ocorre esta influência da internet nas questões relacionadas à política. Não raramente se vê, nos debates acadêmicos, bem como nas conversas informais, pessoas comentando o uso de robôs ${ }^{5}$ como tática de convencimento e direcionamento das opiniões dos indivíduos conectados à internet.

A existência destes robôs, constituídos por algoritmos, bem como a sua participação na vida cotidiana, há pelo menos duas décadas, era algo restrito à ficção científica e imaginação das pessoas. Entretanto, com a evo-

\footnotetext{
${ }^{5}$ Robôs, ou bots, são um tipo específico de programa de computador que realiza tarefas de forma autônoma, a partir de algoritmos. São programados para executar uma série de funções, de facilitar a navegação na internet até a interação com seres humanos (LAGO; MASSARO; CRUZ, 2018).
} 
lução tecnológica houve uma mudança de paradigma, que resultou na utilização de robôs em ambientes inimagináveis. Um destes ambientes foi o da "construção da opinião pública, na escolha subjetiva do eleitor por seus candidatos, na participação direta dos rumos da democracia” (LEAL; MORAES FILHO, 2019, p. 344).

Segundo pesquisas da FGV DAPP, quando do primeiro estudo acerca de robôs, foram identificadas contas automatizadas em momentos relevantes da política brasileira nos últimos anos. Traz como exemplo a greve geral do início do ano de 2017, em que foram identificadas mais de $20 \%$ das interações no Twitter a favor das greves, oriundas de contas desta natureza. Em outro momento, nas eleições de 2014, foi identificada a presença de robôs em pelo menos 10\% dos debates realizados. Com o advento da nova realidade virtual, as estratégias políticas de manipulação do debate público e de inverdades ganharam enorme magnitude, e perderam em transparência (RUEDIGER, 2018, p. 14).

Conforme são designados objetivos e metas, desenvolvidos a partir das vontades do(s) programador(es), os robôs apresentarão determinadas características e comportamentos interacionais com perfis humanos. Com o desenvolvimento da Inteligência Artificial ${ }^{6}$, estes robôs adquirem cada vez mais as características dos pensamentos humanos, transformando seu comportamento em algo complexo e dificultando a identificação da origem virtual da máquina (RUEDIGER, 2018, p. 15). Em razão disto, Rosa (2020, n.p) aponta que:

O algoritmo é um conjunto de instruções para a máquina executar tarefas de pesquisa, comparação e elaboração de propostas/predição de interpretações/aplicações. Por isso é importante assegurar participação democrática no planejamento dos algoritmos.

Ademais, no processo de construção de uma maior participação social conectada à internet, surge um problema muito discutido, nas rodas de conversas informais, dentro das pesquisas acadêmicas e também na prática jurídica: as chamadas fake news.

6 “[...] sistema algorítmico adaptável e relativamente autônomo, emulatório da decisão humana", programado para cumprir objetivos específicos. Mostra-se mais complexa do que a automação pois incorpora a propriedade de produzir, indo além da mera reprodução (FREITAS; FREITAS, 2020, p. 13-15; 27-30). 
Este termo, cujo significado pode ser traduzido para o português como "notícias falsas", é um fenômeno mundialmente conhecido, de disseminação de informações mentirosas, por qualquer meio de comunicação, que tem o conhecimento das inverdades divulgadas, com a finalidade de atrair a atenção dos receptores para desinformar, obter vantagem econômica e/ou política. O ambiente ideal para aflorar este tipo de discurso é a internet, sobretudo em meios de comunicação pouco ou não regulados (BRAGA apud PEREIRA, 2018, p. 205). Tais notícias inverídicas, pelo excesso de repetição e difusão, acabam por se tornar "verdadeiras" a receptores que não têm interesse ou perícia para buscar a fonte. Geralmente, conforme aduz Horbach (2019, p. 51-52), vêm acompanhadas de "apelo emocional, falacioso e subjetivo, não comprovado através da veracidade e de atestados, enganando o receptor da notícia”. Tais práticas são anteriores ao advento da internet, entretanto, com o surgimento desta tecnologia, ganharam em velocidade de disseminação, favorecendo seus efeitos.

$\mathrm{Na}$ política, este fenômeno ganha uma proporção ainda maior de preocupação, visto que fomenta a polarização, impedindo debates. Com esta restrição ao debate, somada a uma enorme veiculação de informações falsas, os indivíduos ficam cada vez mais longe das informações reais (SODRÉ; VALDUGA apud ALVES; CRUZ; PILAU SOBRINHO, 2020). Em termos políticos, existem vertentes que apontam a eleição do ex-Presidente Donald Trump nas eleições estadunidenses em 2016 como beneficiária destes subterfúgios. Ainda que seja uma corrente majoritária, mas não unânime de que realmente foram utilizadas fake news para favorecer o político em estudo, não pode ser prontamente descartada a afirmação, visto que existem pesquisas que indicam a divulgação de 115 notícias falsas que favoreceram a campanha do então candidato, compartilhadas mais de 30 milhões de vezes, ao passo que sua adversária, Hillary Clinton, obteve 41 fake news a seu favor, compartilhadas 7,6 milhões de vezes (BRAGA apud PEREIRA, 2018, p. 205).

Um dos casos de maior repercussão envolvendo a candidata democrata ao pleito envolveu a falsa acusação de que ela participara de crimes tais como tráfico, sequestro e abuso de crianças, e que tais atos eram cometidos no fundo de uma pizzaria em Washington. Os prejuízos causados pela desinformação em tela foram tão graves a ponto de o proprietário do estabelecimento sofrer diversas ameaças de morte, enviadas por mensagens, 
além da tentativa desesperada das partes prejudicadas em desfazer o boato, às vésperas das eleições (FARIA, 2020, p. 163).

Referente ao tema, o Instituto Reuters, da Universidade de Oxford, em seu relatório Digital News, expôs que mais da metade da amostra global expressa preocupação em relação ao que é real e o que é falso quando se trata de notícias online. É importante demonstrar que, neste contexto, o país no topo da lista é o Brasil, onde $85 \%$ dos cidadãos questionados expressam preocupação ou grande preocupação no que tange à desinformação. Logo após, têm-se a Espanha, o Reino Unido e os Estados Unidos, países cuja recente realidade política também mostra-se polarizada por eleições ou campanhas de referendos, que são afetados diretamente pela desinformação, ao passo que países não polarizados, como Holanda e Alemanha, têm índices menores de preocupação em relação ao tema ${ }^{7}$.

Com efeito, o desenvolvimento de programas e softwares formados por algoritmos não tem um caráter neutro, visto que geram efeitos e sua criação e desenvolvimento servem para finalidades determinadas. Ainda que sejam invisíveis e imateriais, têm um ponto de partida e um desígnio original, ainda que possa ser alterado pelos usuários ou pelo próprio algoritmo, nos casos em que tenha embutido no seu código rotinas de autocorreção e aprendizagem. Em suma, estes algoritmos são invenções humanas, e diante desta realidade, guardam consigo as intenções de seus criadores. Esta informação é especialmente importante, visto que nascem, em geral, no âmbito privado, desenvolvidos por empresas privadas, que podem ter o condão, ainda que implícito, de influenciar nos gostos, práticas, opiniões e modos de classificação e visão dos seres humanos (SILVEIRA, 2017).

É notável que o avanço da tecnologia se dá a passos maiores que os da legislação. Para que se entenda os processos políticos e movimentos sociais nos dias atuais, é primordial que haja um estudo mais aprofundado das novas tecnologias. Nessa conjuntura, as "análises acerca dos robôs, os dados pessoais coletados e os critérios e formas nos quais estão sendo utilizados para cada situação não são informados com transparência" (LEAL; MORAES FILHO, 2019, p. 354), o que resulta numa insegurança político-democrática.

Diante de tal cenário, é visível a preocupação do cidadão diante da falta de um filtro de veracidade das informações que consomem diaria-

Disponível em: https://reutersinstitute.politics.ox.ac.uk/sites/default/files/2019-06/ DNR_2019_FINAL_1.pdf. Acesso em: 10 mar 2021. 
mente. Ao mesmo tempo, há um sério perigo para as liberdades individuais, de imprensa e expressão, caso houvesse alguma espécie de regulação das informações. As fake news, nocivas à Democracia, podem justificar a restrição às liberdades mencionadas, desde que atentem contra a Constituição e as instituições democráticas, mas o modo pelo qual se dará essas restrições deve ser objeto de sérios debates, do contrário, servirá de motivação para injustiças.

Num mundo globalizado, há a necessidade de facilitar e restringir, simultaneamente, os fluxos. Entretanto, tais fluxos viabilizam o aparecimento de um lado obscuro da globalização, derivado das incertezas criadas por meio da interconexão viabilizada pelo fenômeno globalizatório. Destas incertezas, são geradas demandas por novos mecanismos, que as neutralizem (MENEZES NETO; MORAIS, 2018). Não poderia ser diferente em relação à comunicação e à internet. Dentre as formas de combater os efeitos nocivos da tecnologia no processo democrático, destacam-se as legislações e as políticas e ferramentas desenvolvidas por empresas responsáveis pelas redes sociais online.

No que diz respeito à legislação, no Brasil por exemplo, existem diversas propostas legislativas a respeito do tema. Em pesquisa no sítio da Câmara dos Deputados na internet, em março de 2021, denota-se que somente neste ano já se aborda a temática em 14 Projetos de Lei ${ }^{8}$. Entretanto, cabe insistir no fato de que, em que pese seja urgente a necessidade de combate a estes problemas, é igualmente importante que não seja subtraída a liberdade de expressão, sendo necessário um estudo aprofundado para definir quais são os parâmetros de classificação de criação ou disseminação de uma notícia falsas. Quanto ao papel das empresas responsáveis pelas redes sociais online, vê-se que há uma maior preocupação em identificar as notícias falsas e proporcionar informações mais acuradas aos usuários.

Com o intuito de responder às demandas sociais oriundas de intensos debates acerca do caso das eleições estadunidenses, a rede social Facebook informou que adotaria uma série de medidas visando certificar a veracidade das informações postadas, tais como a possibilidade de um usuário denunciar a postagem como falsa, que posteriormente passará por uma análise de conteúdo (FARIA, 2020, p. 163). Medidas semelhantes fo-

\footnotetext{
${ }^{8}$ BRASIL. Congresso. Câmara dos Deputados. Disponível em: https:/ /www.camara.leg. br/busca-portal?contextoBusca $=$ BuscaProposicoes\&pagina $=1 \&$ order $=$ relevancia\&abaEspecifica $=$ true\&q $=$ fake $\% 20$ news. Acesso em 19 mar 2021.
} 
ram adotadas pelas redes sociais Twitter e Instagram, após a massificada disseminação de fake news acerca da pandemia e efeitos da Covid-19 e os ataques às instituições democráticas nos Estados Unidos da América, sendo a principal medida a sinalização de conteúdo como falso, ou potencialmente falso ${ }^{9}$ e, ainda, proibição de compartilhamento por risco de incitação à violência ${ }^{10}$.

Por fim, há também a possibilidade de utilização das Fact-checking, uma política de contenção de informações falsas por meio de Inteligência Artificial. O objetivo deste mecanismo é o de aumentar o conhecimento disponível, com a emissão de relatórios acerca de pesquisa de alegados fatos contidos em declarações de políticos ou personalidades capazes de impactar a população. A partir destes dados, sem qualquer vinculação partidária que coloque em xeque a credibilidade da ferramenta, fornece informações claras e rigorosamente controladas aos consumidores, permitindo-lhes fazer escolhas conscientes e livres quando do exercício democrático (HORBACH, 2019, p. 80-82).

Portanto, vê-se que os próprios algoritmos, a internet, as redes sociais online, ou seja, todo o aparato tecnológico posto à disposição, bem como as próprias legislações, podem servir como um contraponto à desinformação, atuando preventivamente, no sentido de prevenir a população acerca do risco que uma escolha guiada por meio de informações falsa pode trazer para a vida particular e para a vida em sociedade, quando se há apenas uma emulação de autonomia na escolha política.

\section{CONSIDERAÇÕES FINAIS}

Quando se trata de Democracia, há um certo consenso em relação à adesão das pessoas a este regime. Em tese, é nele que se pode garantir direitos, deveres, liberdades, obrigações e, principalmente, oferecer a possibilidade de escolha dos representantes pelos representados.

Num regime aparentemente democrático, foi demonstrado que as deliberações e decisões a respeito da vida em sociedade, ainda que tomadas por pessoas eleitas para estas finalidades, passa pelo poder de decisão de uma maioria, que consensualmente escolhe o que julga ser a melhor escolha.

9 Disponível em: https://gizmodo.uol.com.br/facebook-informacoes-falsas-coronavirus/. Acesso em: 10 mar 2021.

${ }^{10}$ Disponível em: https://olhardigital.com.br/2021/01/06/noticias/twitter-proibe-compartilhar-post-de-trump-por-risco-de-violencia/. Acesso em: 10 mar 2021. 
Para além desta vontade majoritária, também há o fato de respeito e amparo às minorias, que merecem salvaguarda, e intervenções pontuais nos diversos domínios da vida por parte de um Estado Democrático e de Direito. Ou seja, pode-se dizer que em um Estado em que prevaleça a Democracia, os cidadãos enquanto eleitores, têm a garantia de escolher um candidato, dentre os possíveis postulantes ao pleito, ainda que este não seja eleito.

Dentro desta realidade, investigou-se o fenômeno da Representação, demonstrada como poder pelo qual uma pessoa exerce um mandato eletivo em nome de outrem, num processo conhecido como Democracia Representativa. A ideia é de que sejam escolhidos àqueles com maior habilidade política, para que representem os interesses dos cidadãos, especialmente dos grupos responsáveis pela vitória destes representantes nas urnas, sem abdicar da observância do respeito às demais pessoas.

Entretanto, em decorrência da evolução da tecnologia, do avanço dos processos comunicacionais, e da influência de novos atores, muitos autores sustentam que a Democracia atravessa uma crise sem precedentes, principalmente no sentido da Representação.

Neste contexto, os algoritmos seguem o avanço tecnológico e se estabilizam como parte da realidade cotidiana dos seres humanos. Das televisões inteligentes às redes sociais online, os algoritmos estão presentes em grande parte do dia a dia das pessoas, modificando de forma expressiva o modo de viver. Esse método é compreendido pela adoção de instruções e regras encadeadas de modo lógico e com informações e finalidades predeterminadas pelo programador e, por vezes, redefinidas pelos próprios algoritmos, com vistas a oferecer soluções e resultados.

A difusão da comunicação, facilitada pelas redes sociais online, contribuiu para que pessoas com ideologias similares pudessem dirimir o problema das barreiras físicas, e construir movimentos capazes de construir ou derrubar governos.

Se por um lado esta aproximação pode ser entendida como um avanço, visto que contribui para a difusão de movimentos que buscam melhorar o status quo social, de outra sorte a desinformação, as informações falsas podem dizimar o desenvolvimento de uma Democracia, visto que a população poderá aderir a um partido, candidato ou movimento que diverge de valores democráticos. 
As fake news, ou notícias falsas, se tornaram um fenômeno mundial, consistente num método de disseminação de informações enganosas com o intuito de atrair a atenção dos receptores, com o objetivo de obter alguma vantagem, seja econômica ou política. Dentro do mundo dos algoritmos, com a velocidade e facilidade de difusão das notícias, estas notícias encontram um ambiente ideal para aflorar. Ademais, por vezes trazem consigo um discurso de ódio, com a finalidade de destruir reputações, facilitando os objetivos detrás da divulgação destas notícias.

Em que pese a disseminação das informações falsas seja uma forma de influenciar negativamente a livre escolha democrática, denota-se que, por pressão social, a classe política está preocupada em oferecer respostas aos impactos causados pela disseminação de notícias falsa, conforme demonstrado com a exposição da enorme quantidade de Projetos de Lei acerca do tema. Ademais, há um esforço por parte de empresas privadas de tecnologia em oferecer resposta a estas demandas, seja por meio de um alerta acerca da veracidade de uma publicação ou a supressão ou banimento de um perfil por violar estas regras, ou pelo desenvolvimento de mecanismos de apuração de autenticidade de uma notícia.

Portanto, fica claro que a Democracia, a Representação e o exercício democrático, de livre escolha, por vezes sucumbe frente à influência de algoritmos responsáveis pela disseminação de notícias falsas e discurso de ódio, sendo importante que haja um trabalho conjunto da sociedade, das instituições políticas e das empresas privadas de tecnologia para que sejam amenizados os efeitos nocivos das fake news.

\section{Referências}

\section{ABREU, Pedro Manoel. O processo jurisdicional como locus da demo-} cracia participativa e da cidadania inclusiva. Tese (Doutorado em Direito) - Universidade Federal de Santa Catarina, 2008.

BOBBIO. Norberto. O futuro da democracia. Tradução de Marco Aurélio Nogueira. 11. ed. São Paulo: Paz e Terra, 2000. (Título original: Il futuro della democrazia).

BRAGA, Renê Morais da Costa. A indústria das fake news e o discurso de ódio. In: PEREIRA, Rodolfo Viana (org.). Direitos políticos, liberdade de expressão e discurso de ódio. v. 1. Belo Horizonte: IDDE, 2018. p. 203-220. 
CASTELLS, Manuel. Redes de indignação e esperança. Movimentos sociais na era da internet. Tradução de Carlos Alberto Medeiros. Rio de Janeiro: Zahar, 2012. (Título original: Networks of Outrage and Hope. Social Movements in the Internet Age).

COTTA, Maurizio. Representação Política. In: BOBBIO, Norberto; MATTEUCCI, Nicola; PASQUINO, Gianfranco. Dicionário de política. 13. ed. UNB: Brasília, 2007. p. 1101-107.

CRUZ, Paulo Márcio. Política, poder, ideologia \& estado contemporâneo. 3. ed. Curitiba: Juruá, 2002.

DAHL, Robert A. Sobre a democracia. Tradução de Beatriz Sidou. Brasília: Editora Universidade de Brasília, 2001. (Título original: On democracy).

FARIA, Fernando de Castro. Democracia e partidos em crise: a busca por respostas. Curitiba: Íthala, 2020.

FERRAJOLI, Luigi. Poderes salvajes: la crisis de la democracia constitucionali. Tradução para o espanhol de Perfecto Andrés Ibánez. Madrid: Minima Trotta, 2011. (Título original: Poteri selvaggi).

FREITAS, Juarez; FREITAS, Thomas Bellini. Direito e inteligência artificial: em defesa do humano. Belo Horizonte: Forum, 2020.

GOFFEY, Andrew. Algorithm. In: Matthew Fuller (org.). Software Studies: a Lexicon, Cambridge, MA: MIT Press, 2008. p. 16.

GORCZEVISKI, Clóvis; FRIDERICH, Denise Bittencourt. Movimentos sociais: construindo alternativas para superar os limites da democracia representativa. Revista Novos Estudos Jurídicos, v. 24. n. 3. set-dez. 2018.

HESSEL, Stéfhane; MORIN, Edgar. E1 camino de la esperanza: una llama a la movilización cívica. Traducción de Rosa Alapont. Barcelona: Ediciones Destino, 2012.

HORBACH, Lenon Oliveira. Fake news: uma abordagem em face da liberdade de expressão, internet e democracia. Dissertação (Mestrado em Direito Público). Universidade do Vale do Rio dos Sinos, 2019.

KELSEN, Hans. A democracia. Tradução de Ivone Castilho, Jefferson Luiz Camargo, Marcelo Brandão Cipolla e Vera Barkow. 2 ed. São Paulo: Martins Fontes, 2000. 
LAGO, Lucas; MASSARO, Heloísa (coord.); CRUZ, Francisco Brito (colab.). Bots ou não? Um estudo preliminar sobre o perfil dos seguidores dos pré-candidatos à Presidência da República no Twitter. InternetLab. São Paulo, 2018. Disponível em: https://www.internetlab.org.br/wp-content/uploads/2018/07/ Relat\%c3\%b3rio-Bots-ou-n\%c3\%a3o.pdf. Acesso em: 19 mar. 2021.

LEAL, Luziane de Figueiredo Simão; MORAES FILHO, José Filomeno de. Inteligência Artificial e Democracia: os algoritmos podem influenciar uma campanha eleitoral? Uma análise do julgamento sobre o impulsionamento de propaganda eleitoral na internet do Tribunal Superior Eleitoral. Revista Direitos Fundamentais \& Justiça, Belo Horizonte, ano 13, n. 41, p. 343356, jul.-dez. 2019.

LUHMANN, Niklas. A improbabilidade da comunicação. Lisboa: Vega, 2006.

MELO, Osvaldo Ferreira de. Dicionário de direito político. Rio de Janeiro: Forense, 1978.

MENEZES NETO, Elias Jacob de; MORAIS, José Luís Bolzan de. Análises computacionais preditivas como um novo biopoder: modificações do tempo na sociedade dos sensores. Revista Novos Estudos Jurídicos. v. 24. n. 3. set.-dez. 2018.

PASOLD, Cesar Luiz. Metodologia da pesquisa jurídica: teoria e prática. 14. ed. rev. atual. e amp. Florianópolis: EMais, 2018.

ROSA, Alexandre Morais da. Inteligência artificial e Direito: ensinando um robô a julgar. Revista Consultor Jurídico, 4 set. 2020.

RUEDIGER, M. A. (coord.). Robôs, redes sociais e política no Brasil: casos de interferências ilegítimas no debate público por automação de perfis. Caderno de referência. v. 2. Rio de Janeiro: FGV DAPP, 2018.

SASSEN, Saskia. Sociologia da globalização. Artmed: Porto Alegre, 2010.

SILVEIRA, Sergio Amadeu. Governo dos Algoritmos. Revista de Políticas Públicas, v. 21, n. 1, p. 267-281, 2017.

SILVEIRA, Sérgio Amadeu. Democracia e os códigos invisíveis: como os algoritmos estão modulando comportamentos e escolhas políticas. v. 1. São Paulo: Edições SESC-SP, 2019. 
SODRÉ, Isabela Camargo; VALDUGA, Gabriela Luzzi. O processo eleitoral na era digital: o combate à desinformação resguardando a democracia. In: ALVES, Paulo Roberto Ramos; CRUZ, Paulo Márcio; PILAU SOBRINHO, Liton Lanes (org.). Jurisdição constitucional, democracia e relações sociais: direitos humanos e cidadania. Itajaí: Univali, 2020.

TOCQUEVILLE, Alexis. A democracia na América: leis e costumes. Tradução de Eduardo Brandão. 2. ed. São Paulo: Martins Fontes, 2005.

TOFFOLI, José Antônio Dias. Fake news, desinformação e liberdade de expressão. 2. ed. São Paulo: Thomson Reuters Brasil, 2020.

José Everton da Silva - Doutor em Ciência Jurídica pela Universidade do Vale do Itajaí (Univali). Diretor da Escola de Ciências Jurídicas e Sociais. E-mail: caminha@univali.br. ORCID: 0000-0003-1494-8866.

Marcos Vinícius de Almeida e Souza - Doutorando em Ciência Jurídica pela Universidade do Vale do Itajaí (Univali). Bolsista PROEX - CAPES. E-mail: viniiciusalmeida@edu.univali. br. ORCID: 0000-0003-3478-2197.

Matheus de Andrade Branco - Doutorando em Ciência Jurídica pela Universidade do Vale do Itajaí (Univali). Advogado. Professor Titular do curso de Direito da Univali. E-mail: matheusdab@gmail.com. ORCID: 0000-0002-7394-6222. 
